\title{
Rural and Remote Health
}

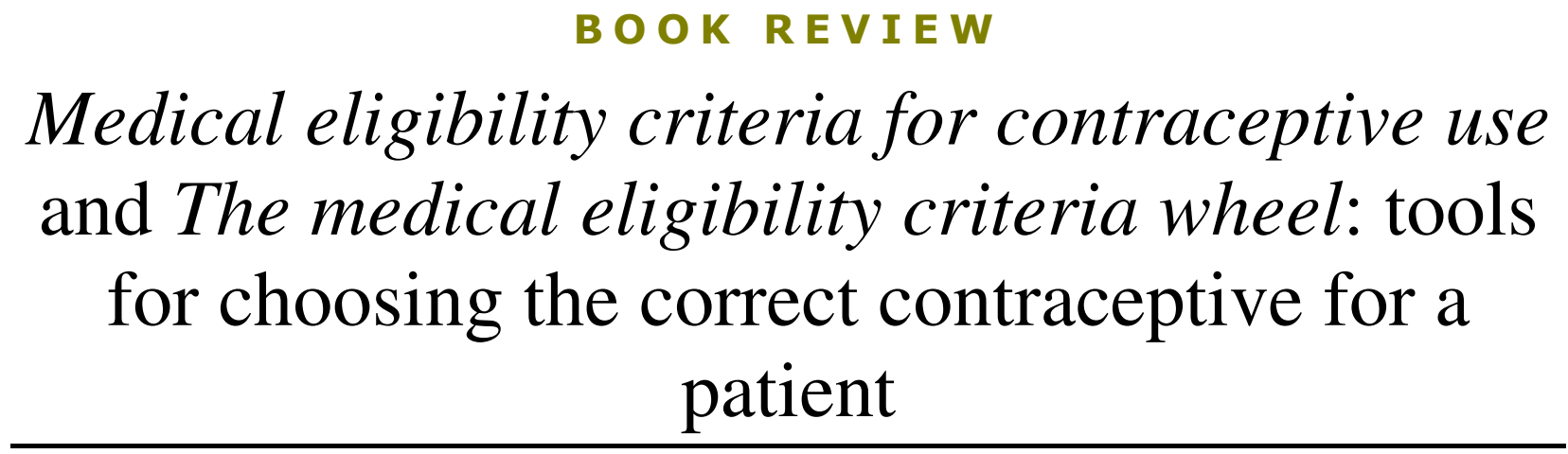

RP Shankar

Manipal College of Medical Sciences, Pokhara, Nepal

Submitted: 29 May 2007; Published: 19 June 2007

Shankar RP

Medical eligibility criteria for contraceptive use and The medical eligibility criteria wheel: tools for choosing the correct contraceptive for a patient

Rural and Remote Health 7: 795. (Online), 2007

Available from: http://www.rrh.org.au

MEDICAL ELIGIBILTYY

CRITERIA FOR

CONTRACEPTIVE USE

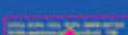

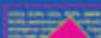

Medical eligibility criteria for contraceptive use, 3rd edition World Health Organisation

Geneva: WHO, 2004

In English, French, Spanish, Russian and Portugese Full text available free of charge:

http://www.who.int/reproductive-health/publications/ mec/ index.htm

ISBN: 9241562668 


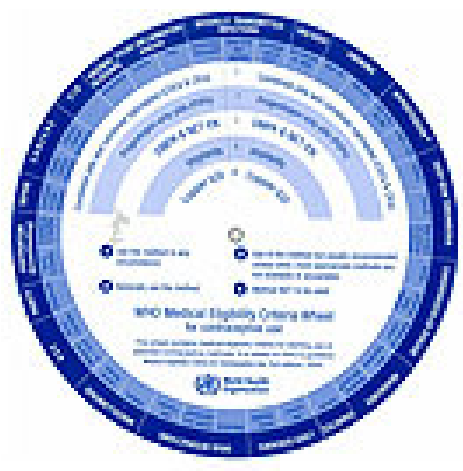

The Medical eligibility criteria wheel for contraceptive use World Health Organisation

Geneva: WHO, 2007

Wheel components available free of charge:

http://www.who.int/reproductive-health/publications/ mec/index.htm

ISBN: 9789241547093

Contraception and the correct use of contraceptives are important issues considering the rapid growth of the world's population, especially in developing countries. Physicians and other health workers in rural and remote areas have an important role to play in providing contraceptive services.

This WHO manual, Medical eligibility criteria for contraceptive use covers low-dose combined oral contraceptives, the combined patch, combined vaginal ring, progestogen-only pills, depot medroxyprogesterone acetate (DMPA), norethisterone enantate (NET-EN), implants, emergency contraceptives, intrauterine devices, barrier methods, sterilization and natural methods of contraception.

Each section starts with a description of the topics to be covered. The book follows a very practical format. Various conditions have been listed and the use of a particular contraceptive in a condition has been described. There is a detailed list of references after each section. Annex 1 discusses combined oral contraceptives and the antiretroviral therapies. This is of special importance considering the rapid spread of HIV.
The book is well produced and the binding is strong to withstand frequent and rough handling. The dark blue colour of the cover jacket makes it especially attractive.

The book's companion The medical eligibility criteria wheel for contraceptive use provides a unique approach to the medical criteria for starting contraceptive use. The wheel has been wonderfully designed and is very easy to use. It would be helpful for family planning providers in deciding whether a particular contraceptive method can be used in a patient with a particular condition. Rural physicians, especially in developing countries, who may not have access to literature or a second opinion from other clinicians will find the wheel very helpful. Six common types of contraceptives are described, namely: combined pills, combined injectable contraceptives, progestin-only pills, copper bearing IUDs, progestin-only implants and the injectables DMPA and NET-EN.

The wheel makes choosing a contraceptive a simple process. It matches the contraceptives shown on the inner disk with specific medical conditions shown around the outer rim. The numbers 1 to 4 shown in the viewing slit tell the healthcare professional whether the particular woman with a specific condition or disease can be prescribed a specific contraceptive method.

The wheel was developed by the World Health Organization in collaboration with Communication Partnership for Family Health in Jordan, Johns Hopkins Center for Communication Programs and the University of Ghana Medical School. The book and the wheel are especially suited for use in the field. Rural and remote clinicians will find them especially useful.

P Ravi Shankar, MD Department of Pharmacology Manipal College of Medical Sciences Pokhara, Nepal 